\title{
4-(D-Glucosamino)-7-nitrobenzoxadiazole: synthesis, anomers, spectra, TLC behavior, and applications
}

\author{
Marioara Bem, ${ }^{a}$ Florin Badea, ${ }^{\mathrm{b}}$ Constantin Draghici, ${ }^{\mathrm{c}}$ Miron Teodor Caproiu, \\ Marilena Vasilescu, ${ }^{\mathrm{a}}$ Mariana Voicescu, ${ }^{\mathrm{a}}$ Gabriela Pencu, ${ }^{\mathrm{d}}$ Adrian Beteringhe,

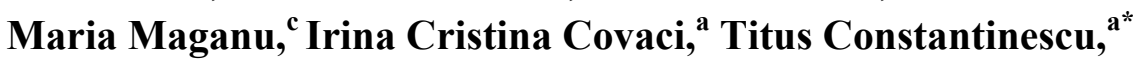 \\ and Alexandru T. Balaban ${ }^{\mathrm{e}^{*}}$
}

${ }^{a}$ Romanian Academy, "Ilie Murgulescu” Institute of Physical Chemistry, Laboratory of Coordinative and Supramolecular Chemistry, Splaiul Independentei 202, 060021, Romania

${ }^{b}$ Politehnica University Bucharest, Department of Organic Chemistry, Splaiul Independentei 313, Bucharest, Romania

${ }^{c}$ Romanian Academy, “C. D. Nenitzescu” Institute of Organic Chemistry, NMR Department, Splaiul Independentei 202 B, Bucharest, Romania

${ }^{d}$ National Agency for Medicinal Drugs, Aviator Sanatescu Street 48, Bucharest, Romania

${ }^{e}$ Texas A\&M University at Galveston, 5007 Ave. U, Galveston, TX, 77553-1675, USA E-mail: titelconstantinescu@yahoo.com, balabana@,tamug.edu

\begin{abstract}
A new synthesis of the known fluorescent compound 3 [4-(D-glucosamino)-7-nitro-2,1,3benzoxadiazol-4-yl] is reported, starting from D-glucosamine and non-fluorescent 4-aryloxy-7nitrobenzofurazans, 4a-e, 5. The $\alpha$ and $\beta$ anomers are easily interconverted but can be separated by TLC $\left(\mathrm{R}_{\mathrm{f}} \beta>\mathrm{R}_{\mathrm{f}} \alpha\right)$. The non-fluorescent new congener 8 \{2-[N-(2',4',6'-trinitrophenyl)amino]-2-deoxy-D-glucose $\}$ and the related known compound 9 \{2-[N-(2',4'-dinitrophenyl)amino]-2-deoxy-D-glucose $\}$ have anomers that may be seen in NMR spectra, but are too rapidly interconverted for TLC separation. The UV-Vis and fluorescence spectra of $\mathbf{3}$ depend markedly on solvent polarity. The TLC method allows the analytical determination of glucosamine from pharmaceutical preparations by conversion into $\mathbf{3}$ and detection by its fluorescence.
\end{abstract}

Keywords: D-Glucosamine-NBD, N-picryl-D-glucosamine, TLC behavior, fluorescence, conformational studies, analytical determination of glucosamine 


\section{Introduction}

The strong fluorescence of 4-nitrobenzofurazans (NBD) having an aminic nitrogen atom in the 7-position has contributed to the wide use of such compounds as biological test reagents. ${ }^{1-8}$ Moreover, some of these derivatives have antileukemic or immunosuppressive properties. ${ }^{1,2,9}$

Glucosamine (2-amino-2-deoxy-D-glucose) (1) is one of the constituents of chitin, chitosan, and mucopolysaccharides and has important biomedical applications, including pharmaceutical preparations for treating cartilage diseases of joints. ${ }^{10-14}$ Such preparations include often glucosamine hydrochloride or sulfate and chondroitin sulfate.

The fluorescent reaction product between 7-chloro-4-nitrobenzofurazan, (2, NBD-Cl) and glucosamine was described: 2-(N-(7'-nitrobenz-2'-oxa-1',3'-diazol-4'-yl)-amino)-2-deoxy-Dglucose ${ }^{15,16}$ (NBD-NH-Glc, 3). Initially, although ${ }^{1} \mathrm{H}-\mathrm{NMR}$ data showed the presence of two distinct $\alpha$ and $\beta$ anomers, only one TLC spot was detected. ${ }^{15}$ More recently, it was possible to provide evidence for the separated anomers by HPLC. ${ }^{16}$ The mixture of anomers 3 is commercially available for visualizing the transport and cellular metabolism of glucose and its analogs, ${ }^{8,15-33}$ and for the electrophoretic determination of glucosamine. ${ }^{34}$

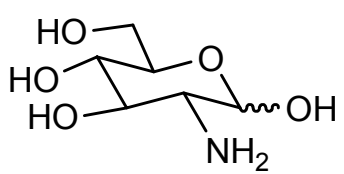

1<smiles>O=[N+]([O-])c1ccc(Cl)c2nonc12</smiles>

2

In the present communication we describe: (i) the TLC separation of the two anomers of $\mathbf{3}$ synthesized from $\mathbf{1}$ and 2; (ii) another synthesis of $\mathbf{3}$ starting from $\mathbf{1}$ and various non-fluorescent 4-aryloxy-7-nitrobenzofurazans 4a-e, $\mathbf{5}^{35-37}$ (ArO-NBD); (iii) the synthesis and characterization of 2-[N-(2',4',6'-trinitrophenyl)amino]-2-deoxy-D-glucose 8, a new analog of the known 2-[N(2',4'-dinitrophenyl)amino]-2-deoxy-D-glucose $9,{ }^{38-43}$ which is a bioanalytical reagent for the spectrophotometric investigation of glucosamine transport and metabolism. The latter compounds 8 and 9 are non-separable mixtures of $\alpha$ and $\beta$ anomers, and the synthesis was based on glucosamine and 2,4,6-trinitrochlorobenzene 6, or 2,4-dinitrofluorobenzene, 7. All compounds have been characterized by elemental analysis, TLC data, RP-TLC (for hydrophobic/hydrophilic balance), NMR, UV-Vis and fluorescence spectra and the solvent effects on all these data. 

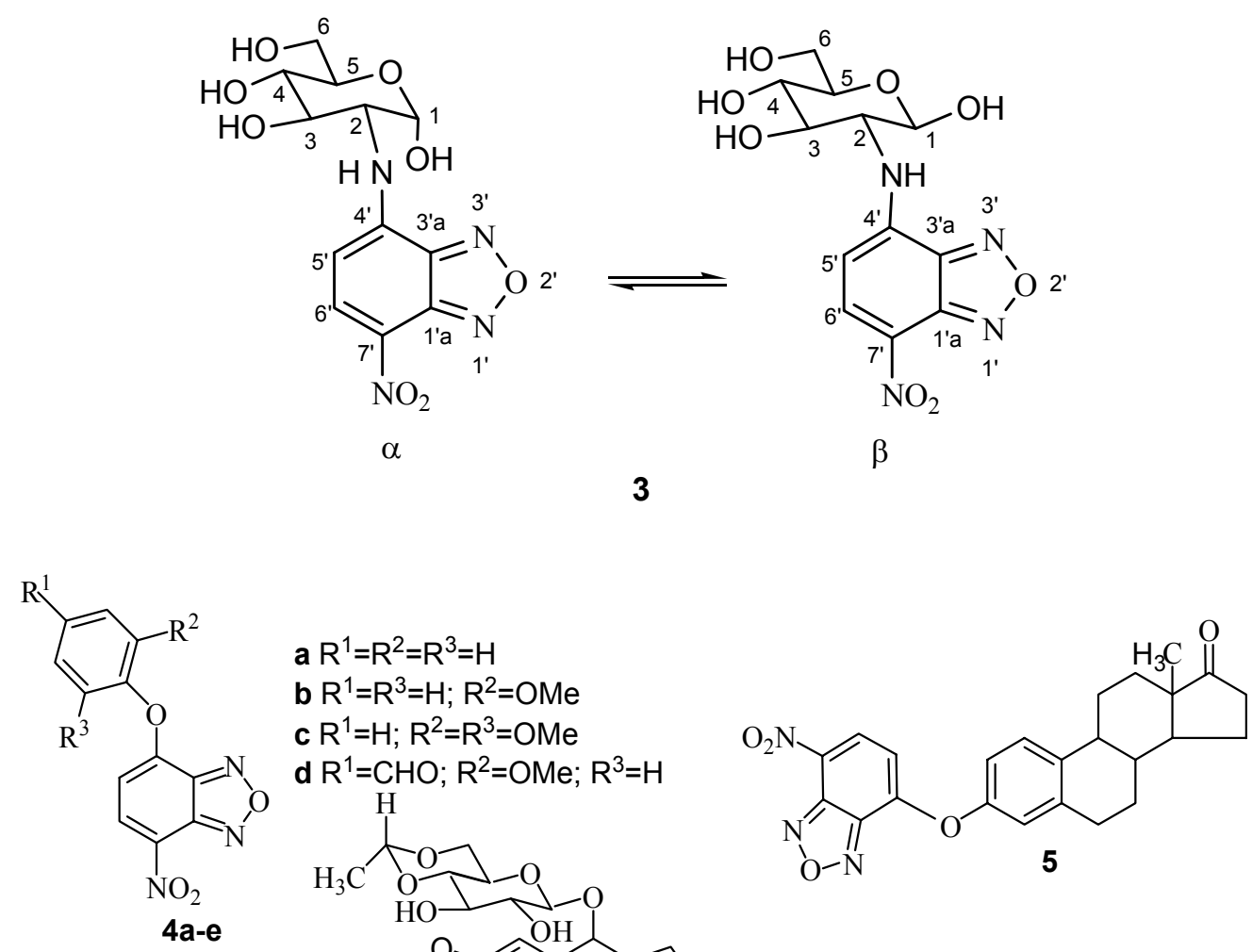

e $\mathrm{R}^{1}$

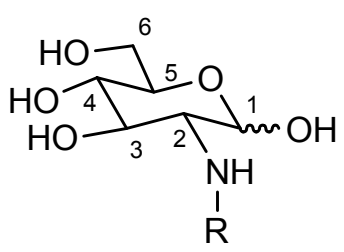

$8(\alpha+\beta): \quad R=$<smiles>O=[N+]([O-])c1cc([N+](=O)[O-])cc([N+](=O)[O-])c1</smiles>

8,9

$9(\alpha+\beta): \quad \mathrm{R}=$<smiles>O=[N+]([O-])c1cccc([N+](=O)[O-])c1</smiles>

\section{Results and Discussion}

\section{Synthesis of compounds 3, 8, and 9}

Two synthetic variants, A and B, were adopted for the formation of $\mathbf{3}$ (Scheme 1). In variant A, the reaction of $\mathbf{1}$ (as hydrochloride) and $\mathbf{2}$ takes place in the presence of sodium hydrogen carbonate in methanol at $50^{\circ} \mathrm{C}$, but the difference from the literature ${ }^{15,16}$ occurs in the isolation and purification via preparative TLC (yield 40\%). In variant B (yield 60\%), based upon the 
previous experience with amino acids ${ }^{37}$ the starting materials were $\mathbf{1}$ (as hydrochloride) and 4aryloxy-7-nitrobenzofurazans 4 a-e or $\mathbf{5}^{35-37}$ at $30^{\circ} \mathrm{C}$, also in the presence of $\mathrm{NaHCO}_{3}$. In both cases the reactions take place in an $\mathrm{S}_{\mathrm{N}} \mathrm{Ar}$ process (Scheme 1) via a deeper-colored Meisenheimer complex.

Like the NBD moiety, polynitrophenyl groups are strongly electron-attracting and they were the prototype for the formation of Meisenheimer complexes. ${ }^{35-37,44}$ By reacting the nucleophile 1 (as hydrochloride) with picryl chloride $\mathbf{6}$ in the presence of $\mathrm{NaHCO}_{3}$, the new compound $\mathbf{8}$ was formed (Scheme 2). In order to obtain in an analogous way the known compound $\mathbf{9},{ }^{38-43}$ the electrophile was 2,4-dinitrofluorobenzene, 7. Although both these compounds give rise to anomers as attested by NMR evidence, TLC does not allow their separation.

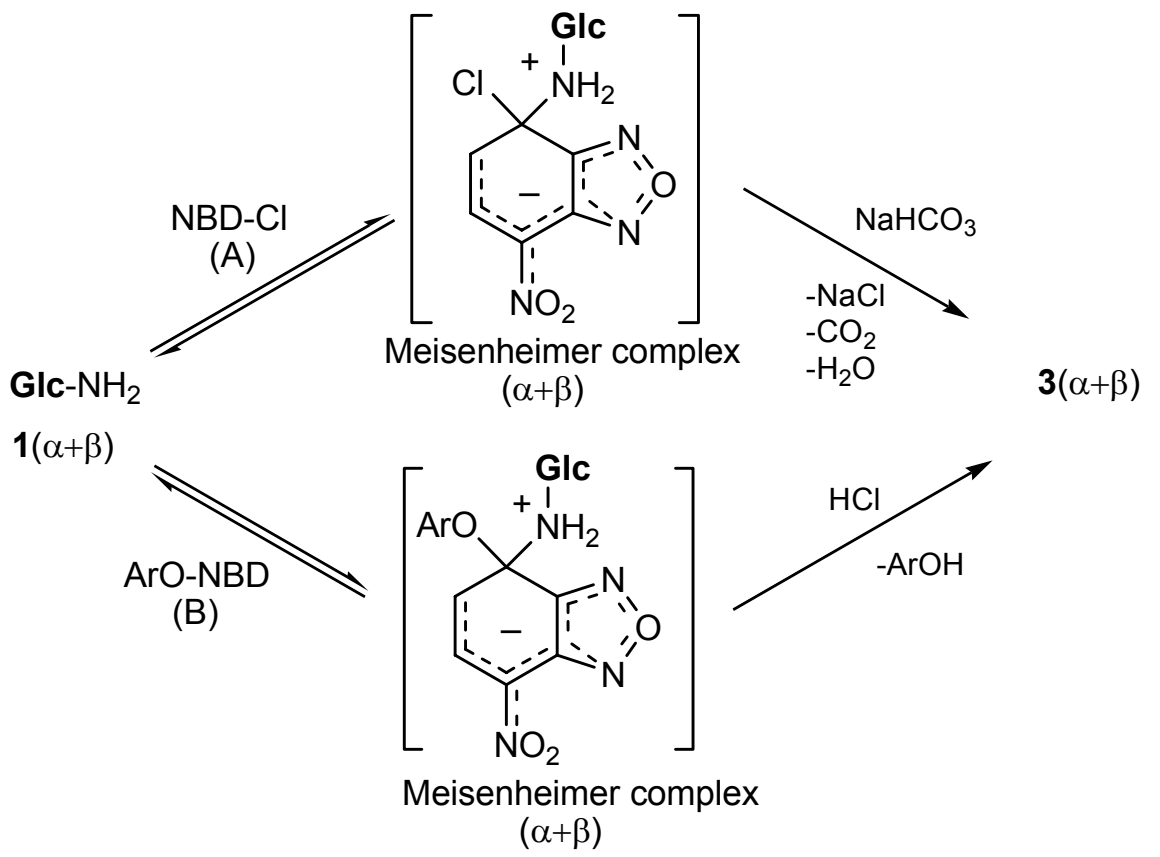

Scheme 1. Synthesis of compound 3 by variants A and B.

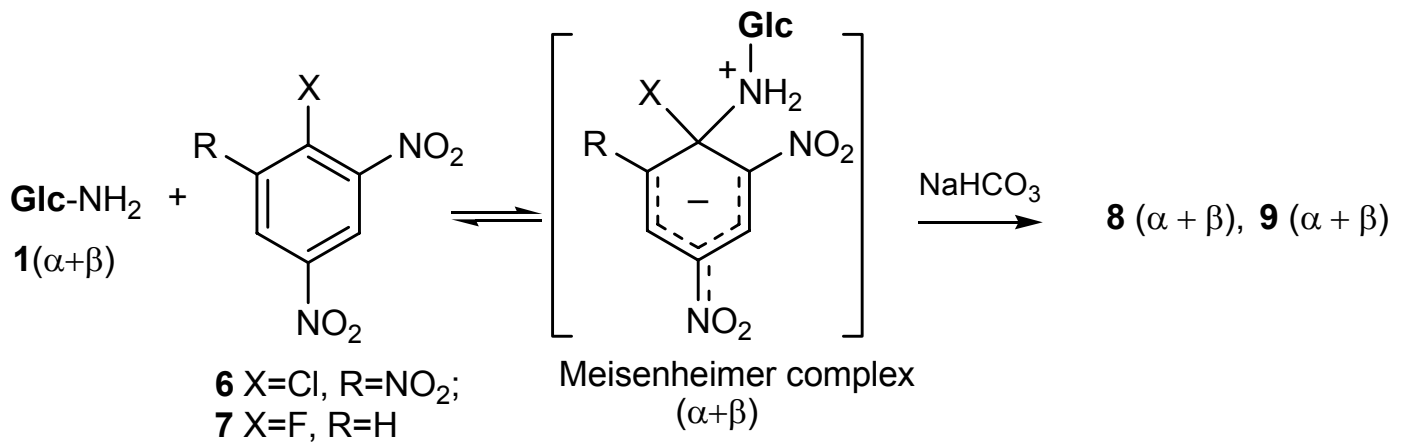

Scheme 2. Synthesis of compounds 8 and 9. 


\section{NMR Spectra}

The ${ }^{1} \mathrm{H}-\mathrm{NMR}$ and ${ }^{13} \mathrm{C}-\mathrm{NMR}$ spectra were recorded in DMSO- $\mathrm{d}_{6}$ with trifluoroacetic acid (the latter allows a better resolution of hydroxyl protons). In the ${ }^{1} \mathrm{H}-\mathrm{NMR}$ spectra of $\mathbf{3}$, characteristic peaks for the NBD moiety correspond to aromatic protons H-6' and H-5', and for the glucosamine moiety to protons bonded to carbons $2,3,4,5$, and 6 . The $\alpha$ anomer is characterized by the H-1 doublet at $5.23 \mathrm{ppm}$ and the $\beta$ anomer by the $\mathrm{H}-1$ doublet at $4.78 \mathrm{ppm}$, similarly to the reported values in deuterium oxide (for $\alpha, \delta=5.27 \mathrm{ppm}$, and for $\beta, \delta=4.78 \mathrm{ppm}$ ). ${ }^{15,16}$ The relative amounts at equilibrium are $\alpha / \beta \approx 1 / 1$, similarly to literature data ${ }^{15}$ (per cent ratio $\alpha / \beta=$ $42 / 58)$. In the ${ }^{13} \mathrm{C}-\mathrm{NMR}$ spectra, characteristic peaks for the NBD moiety correspond to aromatic carbons (C-1'a, C-3'a, C-4', $\left.5^{\prime}, 6^{\prime}, 7^{\prime}\right)$ and for the glucosamine moiety to all six $s p^{3}$-hybridized carbon atoms. ${ }^{45}$

In the ${ }^{1} \mathrm{H}-\mathrm{NMR}$ spectra of $\mathbf{8}$, characteristic peaks for the NBD moiety correspond to aromatic protons $\mathrm{H}-3^{\prime}$ and $\mathrm{H}-5^{\prime}$, and for compound 9 to aromatic protons $\mathrm{H}-3^{\prime}, 5^{\prime}, 6^{\prime}$ '. In both cases, the H$2,3,4,5,6$ peaks are practically identical. For the $\alpha$ anomer of $\mathbf{8}$, the H-1 doublet appears at 5.13 ppm, and for the $\beta$ anomer at $4.79 \mathrm{ppm}$. For the $\alpha$ anomer of 9 , the $\mathrm{H}-1$ doublet appears at 5.23 $\mathrm{ppm}$, and for the $\beta$ anomer at $4.63 \mathrm{ppm}$. Interestingly, the percent ratio for the two anomers differs markedly: $\alpha / \beta \approx 95 / 5$ for $\mathbf{8}$ and $\alpha / \beta \approx 85 / 15$ for 9 . The decreasing $\alpha / \beta$ anomer ratio $8>\mathbf{9}>$ 3 can be explained by the global electronegativity of the aromatic group which decreases in the same order, and also by the decreasing possibility for an intramolecular hydrogen bond between the axial $\alpha$-hydroxy group and the nitro-O atom or the heterocyclic $\mathrm{N}$-atom of the aromatic moiety.

\section{Conformational studies for anomers $3 \alpha, 3 \beta, 8 \alpha, 8 \beta, 9 \alpha$ and $9 \beta$}

It is well known that the interconversion of glucose anomers (mutarotation) is a general acidbase-catalyzed reaction which requires the simultaneous presence of a base and an acid. ${ }^{46,47}$ With mineral acids or bases, the protic solvent provides the missing third partner. However, with phenols as acids and pyridines as bases, which do not undergo neutralization, it was proven that when both are present a marked acceleration occurs. An even higher acceleration occurs with 2pyridone derivatives because a bimolecular process replaces the termolecular encounter.

In our case the equilibration of the two anomers is facilitated by the presence of the relatively acidic NH group so that one has to assume that the $\alpha / \beta$ anomer ratio always corresponds to the equilibrium ratio.

In order to better understand these anomer equilibria, theoretical conformational calculations were undertaken. The molecular geometry was determined by using the Hyperchem program, ${ }^{48}$ and the results of the optimization are presented in Fig. 1. The energies computed with programs WinMOPAC $7.21^{49}$ and CODESSA ${ }^{50}$ are displayed in Table 1. 
Table 1. Energies of $\alpha$ and $\beta$ anomers of compounds 3,8 and 9

\begin{tabular}{|c|c|c|c|c|c|c|}
\hline \multirow{2}{*}{$\begin{array}{c}\text { Energy } \\
(\mathrm{kcal} / \mathrm{mol})\end{array}$} & \multicolumn{6}{|c|}{ Compounds } \\
\hline & $3 \alpha$ & $3 \beta$ & $8 \alpha$ & $8 \beta$ & $9 \alpha$ & $9 \beta$ \\
\hline $\begin{array}{l}\text { Electronic } \\
\text { energy }^{\mathrm{a}}\end{array}$ & -811514.79 & -806423.31 & -1042354.43 & -1042549.79 & -875570.54 & -876014.66 \\
\hline $\begin{array}{l}\text { Zero point } \\
\text { vibrational } \\
\text { energy }^{\text {b }}\end{array}$ & 4289.14 & 4288.90 & 4479.39 & 4836.15 & 4421.05 & 4763.96 \\
\hline HOMO-Energy & -231.19 & -230.49 & -237.06 & -226.82 & -224.70 & -220.74 \\
\hline LUMO-Energy $^{\mathrm{b}}$ & -52.33 & -52.37 & -46.49 & -42.18 & -33.60 & -35.21 \\
\hline Energy $^{\mathrm{a}}$ & -118349.59 & -118350.57 & -141142.78 & -141142.95 & -121947.24 & -121947.47 \\
\hline
\end{tabular}

${ }^{\mathrm{a}}$ WinMOPAC $7.21 .{ }^{49}{ }^{\mathrm{b}}$ CODESSA. ${ }^{50}$

It can be seen that the two anomers of 3 have higher energy differences $\left(\Delta \mathrm{E}_{\mathrm{T}}=\mathrm{E}_{\mathrm{T}} \beta-\mathrm{E}_{\mathrm{T}} \alpha\right)$ than the other compounds: $\Delta \mathrm{E}_{\mathrm{T}(\mathbf{3})}=-0.98 \mathrm{kcal} / \mathrm{mol}, \Delta \mathrm{E}_{\mathrm{T}(\boldsymbol{8})}=-0.17 \mathrm{kcal} / \mathrm{mol}, \Delta \mathrm{E}_{\mathrm{T}(\mathbf{9})}=-0.23$ $\mathrm{kcal} / \mathrm{mol}$. This fact may provide an explanation for the fact that TLC is able to separate only the anomers of 3 .

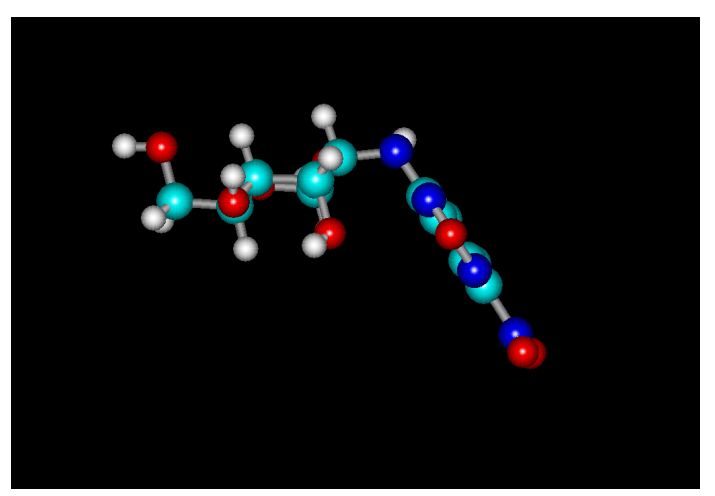

$3 \alpha$

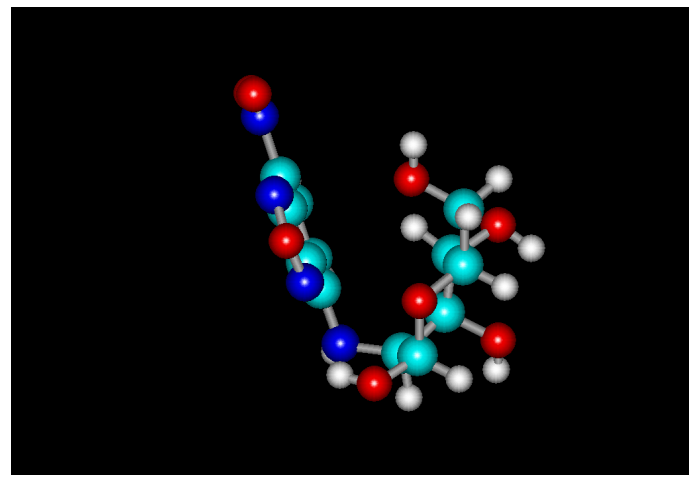

$3 \beta$ 


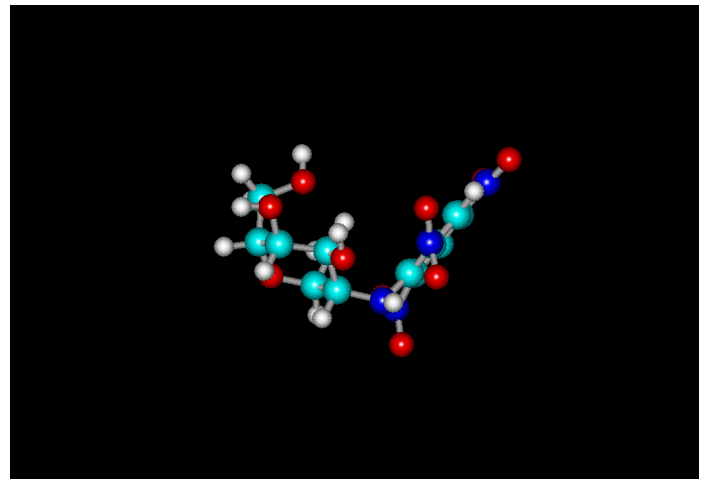

$8 \alpha$

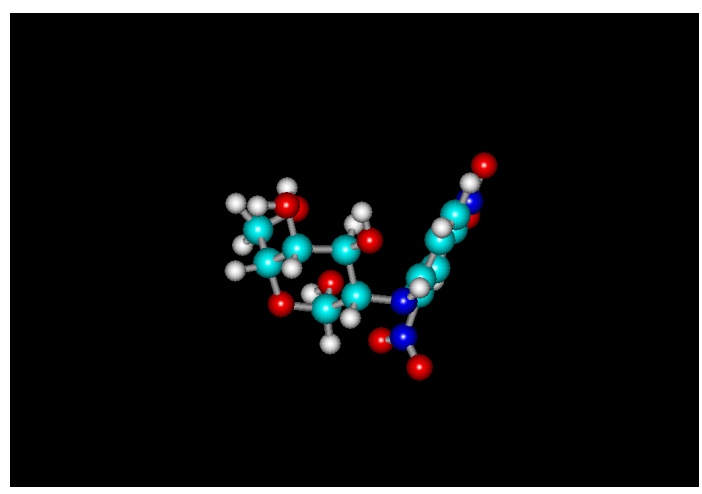

$9 \alpha$

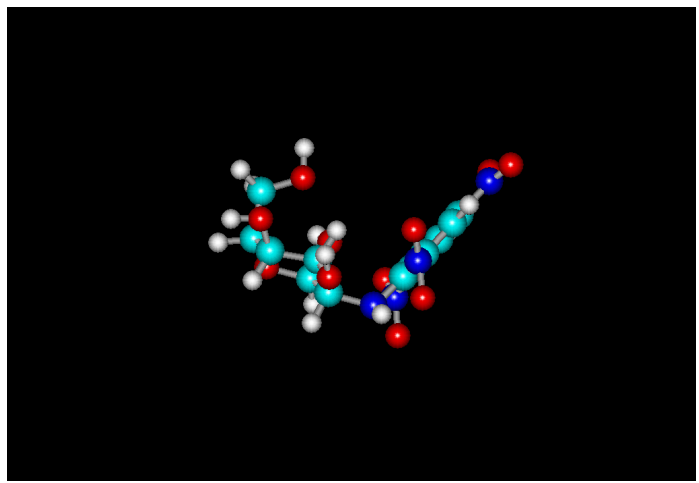

$8 \boldsymbol{\beta}$

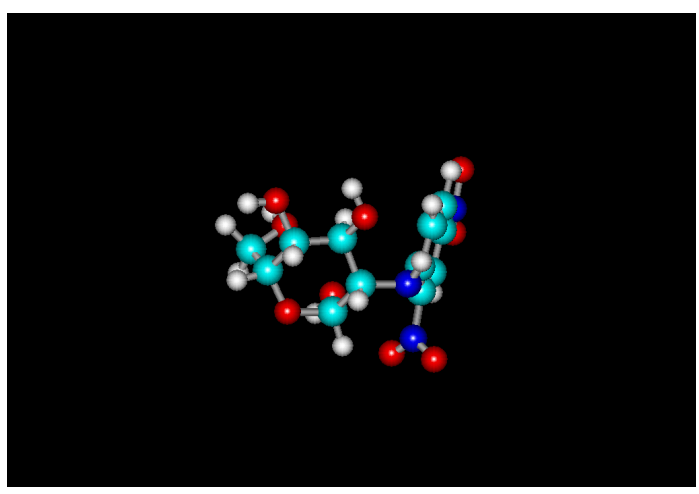

$9 \boldsymbol{\beta}$

Figure 1. Optimized structures (with the MM+ force field from the Hyperchem ${ }^{48}$ program) for $\alpha$ and $\beta$ anomers corresponding to compounds $\mathbf{3 , 8}$ and $\mathbf{9}$.

According to the optimized geometry from Figure 1, the $\alpha$ anomer of $\mathbf{3}$ has an "open" structure favoring stronger interactions with a flat surface, whereas the $\beta$ anomer has a "closed" structure resembling a sandwich with nearly parallel rings. On considering the possibility of an intramolecular hydrogen bond between the NH group and the glycosidic oxygen for compounds 3, 8, and 9 by means of programs Hyperchem ${ }^{48}$ and ArgusLab, ${ }^{51,52}$ it was found (Table 2) that the $\mathrm{O} \cdots \mathrm{N}$ distance in the $3 \beta$ anomer is the lowest (closest to $3 \AA$ ) ${ }^{53} \alpha$ anomers have larger distances. These results may throw light on the differences in retention times due to interactions with $\mathrm{Si}-\mathrm{OH}$ groups of the silica gel stationary phase. 
Table 2. Distance between the nitrogen atom and the glycosidic oxygen computed by means of the Hyperchem program

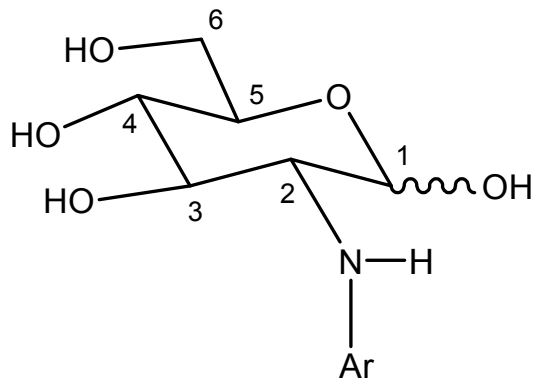

$$
\begin{array}{ll}
\mathbf{3}(\alpha, \beta) & \text { Ar }=\text { NBD } \\
\mathbf{8}(\alpha, \beta) & \text { Ar=Picryl } \\
\mathbf{9}(\alpha, \beta) & \text { Ar=2,4-Dinitrophenyl }
\end{array}
$$

\begin{tabular}{cc}
\hline Compound & Distance $(\AA)$ \\
\hline $\mathbf{3 \alpha}$ & 3.617 \\
$\mathbf{3} \boldsymbol{\beta}$ & 2.954 \\
$\mathbf{8 \alpha}$ & 4.463 \\
$\mathbf{8} \boldsymbol{\beta}$ & 3.098 \\
$\mathbf{9 \alpha}$ & 4.424 \\
$\mathbf{9} \beta$ & 3.088 \\
\hline
\end{tabular}

\section{Thin-layer chromatographic data for anomers of 3}

Room-temperature separations by TLC involving silica gel and a mixture of dichloromethane and methanol in three different ratios, presented as (a) - (c) in Table 3, indicated that compound 3 presented two spots ( $\mathrm{X}$ and $\mathrm{Y}$ ) irrespective of the synthesis method (A or B), whereas compounds 8 and 9 always gave rise to only one spot, with retention times $\mathrm{R}_{\mathrm{f}} \mathbf{8}(\alpha+\beta)>\mathrm{R}_{\mathrm{f}} \mathbf{9}(\alpha$ $+\beta)>\mathrm{R}_{\mathrm{f}} 3 \mathrm{X}>\mathrm{R}_{\mathrm{f}} 3 \mathrm{Y}$.

Table 3. TLC behavior $\left(\mathrm{R}_{\mathrm{f}}\right)^{\mathrm{a}, \mathrm{b}}$ of compounds $3,{ }^{\mathrm{c}} \mathbf{8}$, and $\mathbf{9}$

\begin{tabular}{clcc}
\hline Compound & $\mathrm{R}_{\mathrm{f}}(\mathrm{a})$ & $\mathrm{R}_{\mathrm{f}}(\mathrm{b})$ & $\mathrm{R}_{\mathrm{f}}(\mathrm{c})$ \\
\hline $\mathbf{3 ~ X ^ { d }}$ & 0.22 & 0.41 & 0.65 \\
$\mathbf{3} \mathrm{Y}^{d}$ & 0.11 & 0.30 & 0.51 \\
$\mathbf{8}(\alpha+\beta)^{\mathrm{e}}$ & 0.42 & 0.63 & 0.88 \\
$\mathbf{9}(\alpha+\beta)^{\mathrm{e}}$ & 0.31 & 0.52 & 0.77 \\
\hline
\end{tabular}

${ }^{\mathrm{a}}$ Silica gel $\mathrm{GF}_{254}$ (Merck), with (a): methylene chloride: methanol (9:1, v/v); (b): methylene chloride: methanol $(8.5: 1.5, \mathrm{v} / \mathrm{v})$; $(\mathrm{c})$ : methylene chloride: methanol $(8: 2, \mathrm{v} / \mathrm{v})$. ${ }^{\mathrm{b}}$ At room temperature. ' Obtained by $\mathbf{A}$ or $\mathbf{B}$ procedure (Scheme 1). ${ }^{\mathrm{d}}$ Detection by fluorescence $(360 \mathrm{~nm})$. ${ }^{\mathrm{e}}$ Detection at $254 \mathrm{~nm}$.

By using a liquid-liquid partition (silica gel having a covalently-bonded hydrocarbon $\mathrm{C}_{18}$ chain and aqueous ethanol at three concentrations) it was possible to determine both the TLC 
behavior and the hydrophobicity parameter $\mathrm{R}_{\mathrm{M} 0} \cdot{ }^{54-57}$ The results are presented in Table 4 . The statistical parameters $R, F$, and the standard deviation $(S D)$ for $\mathrm{R}_{\mathrm{M} 0}$ are good to excellent.

Table 4. Experimental hydrophobicity $\left(\mathrm{R}_{\mathrm{M} 0}{ }^{\mathrm{a}, \mathrm{b}}\right)$ and calculated $(\log \mathrm{P})^{58}$ for compounds $\mathbf{3}, \mathbf{8}$ and 9

\begin{tabular}{|c|c|c|c|c|c|c|c|c|c|}
\hline \multirow{3}{*}{ Comp. } & \multicolumn{8}{|c|}{ Experimental data } & \multirow{3}{*}{$\begin{array}{c}\text { Calcd. } \\
\log P\end{array}$} \\
\hline & \multicolumn{3}{|c|}{$\mathrm{R}_{\mathrm{M}}$ in aqueous ethanol, conc.(v/v) } & \multirow{2}{*}{$\mathrm{R}_{\mathrm{M} 0}$} & \multirow{2}{*}{$b$} & \multicolumn{3}{|c|}{ Statistical parameters } & \\
\hline & $70 \%$ & $60 \%$ & $50 \%$ & & & $R$ & $F$ & $S D$ & \\
\hline 3 & -0.5006 & -0.6434 & -1.0787 & -2.475 & 0.029 & 0.959 & 11.72 & 0.119 & -0.540 \\
\hline 8 & 0.3273 & -0.0321 & -03521 & -2.057 & 0.034 & 0.999 & 892.1 & 0.016 & -0.280 \\
\hline 9 & 0.1047 & -02303 & -0.5228 & -2.098 & 0.031 & 0.999 & 653.9 & 0.017 & -0.410 \\
\hline
\end{tabular}

${ }^{\mathrm{a}}$ Average for five determination on silica gel RP-18 $\mathrm{F}_{254}$ (Merck) with mixtures of ethanol:water; $\mathrm{R}_{\mathrm{M} 0}=$ molecular hydrophobicity, where $\mathrm{R}_{\mathrm{M} 0}$ is the $\mathrm{R}_{\mathrm{M}}$ value of the organic component extrapolated to zero concentration in the organic:water mixture; $b=$ the change in the $\mathrm{R}_{\mathrm{M}}$ value caused by increasing the concentration $(K)$ of the organic component in the mobile phase; $R=$ the correlation coefficient for parameters $\mathrm{R}_{\mathrm{M} 0}$ and $b$ described by ecuation $\mathrm{R}_{\mathrm{M}}=\mathrm{R}_{\mathrm{M} 0}+b K$ [where $\mathrm{R}_{\mathrm{M}}=\log \left(1 /\left(\mathrm{R}_{\mathrm{f}}-1\right)\right] .^{54-57}$

The results show that under these conditions, all three compounds migrate as an inseparable mixture of the two anomers; the hydrophobicity decreases in the order $\mathrm{R}_{\mathrm{M} 0} 8>\mathrm{R}_{\mathrm{M} 0} 9>\mathrm{R}_{\mathrm{M} 0} 3$, in agreement with the order for the $\alpha / \beta$ anomer ratio and with the known hydrophobicity of nitro groups (trinitrophenyl-aminodeoxyglucose, $8>$ dinitrophenyl- aminodeoxyglucose, $9>$ nitrobenzodioxazolyl-aminodeoxyglucose, 3 ).

On studying the partition in a solid-liquid system when the solvent is aqueous acetonitrile $(17: 3 \mathrm{v} / \mathrm{v})$ as mentioned in the literature for $3,{ }^{15,16}$ a single spot was observed. When there is no water in the mobile phase for stationary phase I, and water for stationary phase II, as in Table 5, two spots can be observed. This is in agreement with the idea that the equilibration $3 \alpha=3 \beta$ occurs rapidly in the aqueous mobile phase due to the general acid-base catalysis.

Since reaction rates are also strongly influenced by the temperature, TLC studies in ethyl acetate at various temperatures with two types of stationary phases (I and II) were carried out and the results are displayed in Table 5. The stationary phase I is the "classical" silica gel, whereas the stationary phase II is silica gel- $\mathrm{C}_{18}$ associated with a copper salt and a chiral derivative for use in separating enantiomers of amino acids. ${ }^{59-61}$ 
Table 5. TLC data of the two spots $X$ and $Y(\beta$ and $\alpha)$ for $\mathbf{3}$ synthesized by variant A

\begin{tabular}{|c|c|c|c|c|c|c|c|c|}
\hline & \multicolumn{2}{|c|}{ Temperature $\left({ }^{\circ} \mathrm{C}\right)$} & \multicolumn{3}{|c|}{$\mathrm{R}_{\mathrm{f}}$} & \multicolumn{3}{|c|}{$\%{ }^{\mathrm{e}}$} \\
\hline $\operatorname{TLC}^{\mathrm{a}}$ & $\begin{array}{c}\text { For } 3 \text { in ethyl } \\
\text { acetate }^{\mathrm{b}}\end{array}$ & $\begin{array}{c}\text { For } \\
\text { mobile } \\
\text { phase }^{\mathrm{c}}\end{array}$ & $\mathrm{X}(\beta)$ & $\mathrm{Y}(\alpha)$ & $\Delta \mathrm{R}_{\mathrm{f}}{ }^{\mathrm{d}}$ & $\mathrm{X}(\beta)$ & $\mathrm{Y}(\alpha)$ & $\mathrm{X}(\beta) / \mathrm{Y}(\alpha)$ \\
\hline \multirow{5}{*}{ I } & 24.2 & 20.7 & 0.21 & 0.13 & 0.08 & 65.05 & 34.87 & 1.86 \\
\hline & 5.4 & 20.7 & 0.28 & 0.20 & 0.08 & 66.08 & 33.85 & 1.95 \\
\hline & 5.5 & 4.75 & 0.46 & 0.34 & 0.12 & 65.81 & 34.08 & 1.93 \\
\hline & 5.4 & 0.15 & 0.52 & 0.38 & 0.14 & 66.07 & 33.73 & 1.95 \\
\hline & 5.7 & -6.7 & 0.93 & 0.69 & 0.24 & 60.08 & 39.87 & 1.50 \\
\hline \multirow{2}{*}{ II } & 23.8 & 22.9 & 0.47 & 0.36 & 0.11 & 40.87 & 59.08 & 0.69 \\
\hline & 5.6 & 14.9 & 0.50 & 0.35 & 0.15 & 38.82 & 61.10 & 0.63 \\
\hline
\end{tabular}

${ }^{a}$ I: TLC analytical plates silica gel $\mathrm{GF}_{254}$ (Merck), $\mathrm{CH}_{2} \mathrm{Cl}_{2}: \mathrm{MeOH} 8.5: 1.5 \mathrm{v} / \mathrm{v}$, front mobile phase $=5 \mathrm{~cm}$; II: HPTLC analytical plates CHIR (Merck), $\mathrm{H}_{2} \mathrm{O}: \mathrm{EtOH} 9: 1$, front mobile phase $=5 \mathrm{~cm}$. ${ }^{\mathrm{b}} 15$ minutes at the indicated temperature. ${ }^{\mathrm{c}}$ Average value (between start and end of the development of the chromatographic determination). ${ }^{\mathrm{b}, \mathrm{c}}$ Measured with digital termometer Diplex $\left(-40^{\circ} \mathrm{C}\right.$ to $\left.200^{\circ} \mathrm{C}\right) .{ }^{\mathrm{d}} \Delta \mathrm{R}_{\mathrm{f}}=\mathrm{R}_{\mathrm{f}} \mathrm{X}-\mathrm{R}_{\mathrm{f}} \mathrm{Y} .{ }^{\mathrm{e}} \mathrm{Q}$ uantitative (densitometric) TLC analysis $\left(\lambda_{\max }=341 \mathrm{~nm}\right)$.

Densitometric TLC determinations show that on summing the chromatographic peak areas, the purity $(>99 \%)$ is confirmed. The data presented in Table 5 indicate that for the stationary phase I the spot with higher $\mathrm{R}_{\mathrm{f}}(\mathrm{X})$ corresponds to the $\beta$ anomer, which prevails in the equilibrium mixture due to its lower steric hindrance and energy. Recently, literature HPLC data revealed a similar elution time order: $t_{R} \beta>t_{R} \alpha{ }^{16}$ Our data presented in Table 5 show the influence of lower temperatures regarding the chromatographic resolution for the anomers $\alpha$ and $\beta$ (the $\Delta \mathrm{R}_{\mathrm{f}}$ value).

For the stationary phase II, due to interactions with the copper complex (known in the case of glucose) ${ }^{62-64}$ the order of migration of the two anomers is not so clear; we assume that the order in which the two anomers migrate becomes reversed, and that the $\beta / \alpha$ ratio does not conserve the prevalence of the $\beta$ anomer in the equilibrium mixture.

The behavior of $\mathbf{3}$ obtained by synthetic variant B is similar to that via variant A: the purity is again $>99 \%$ by densitometric analysis on summing the areas of the two peaks.

\section{UV-Vis and fluorescence spectra of compound $3(\alpha+\beta)$}

Compound $\mathbf{3}$ in crystalline state and in solution is yellow-orange and strongly fluorescent. The longest-wavelength absorption band presents in various solvents a positive solvatochromy: $\lambda_{\max }$ increases with increasing values of Reichardt's empirical solvent polariy parameter, ${ }^{65}$ as one can observe from Table 6.

The fluorescence characteristics, namely $\lambda_{\mathrm{ex}}, \lambda_{\mathrm{em}}$, the quantum yield $\Phi$, natural lifetime $\tau_{0}$ and calculated lifetime $\tau$, also depend on the solvent polarity: with increasing $\mathrm{E}_{\mathrm{T}}(30), \Phi$ and $\tau$ 
(which includes parameter $\Phi$ ) decrease. From Figure 2, one can see that in aqueous ethanol the fluorescence intensity decreases with decreasing ethanol concentration. Also, with decreasing ethanol concentration, one observes a decrease of the fluorescence parameters $\Phi, \tau_{0}$ and $\tau$, in agreement with qualitative literature data about the fluorescence of $\mathbf{3}(\alpha+\beta)$ in water. $^{16}$

These findings are useful for applications of $\mathbf{3}$ as a fluorescent probe for assaying glucosamine, because the adequate choice of solvent is critical for obtaining a satisfactory intensity of fluorescence.

Table 6. UV-Vis spectral data and the fluorescence characteristics: $\lambda_{\mathrm{ex}}, \lambda_{\mathrm{em}}$, quantum yield $(\Phi)$, natural lifetime $\left(\tau_{0}\right)$ and calculated lifetime $(\tau)$ in various solvents for compound $\mathbf{3}(\alpha+\beta)^{\mathrm{a}, \mathrm{b}}$

\begin{tabular}{|c|c|c|c|c|c|c|c|}
\hline $\begin{array}{c}\text { Solvent } \\
\left(\mathrm{E}_{\mathrm{T}}(30)\right)^{65}\end{array}$ & $\lambda_{\max }(\mathrm{nm})$ & $\begin{array}{c}\varepsilon \times 10^{3} \\
\left(\mathrm{~L} \times \mathrm{mole}^{-1} \times \mathrm{cm}^{-1}\right)\end{array}$ & $\begin{array}{c}\lambda_{\mathrm{ex}} \\
(\mathrm{nm})\end{array}$ & $\begin{array}{c}\lambda_{\mathrm{em}} \\
(\mathrm{nm})\end{array}$ & $\Phi^{\mathrm{e}}$ & $\begin{array}{c}\tau_{0} \\
(\mathrm{~ns})^{\mathrm{f}}\end{array}$ & $\tau(\mathrm{ns})^{\mathrm{g}}$ \\
\hline $\begin{array}{c}\text { Ethyl acetate } \\
\quad(38.1)\end{array}$ & $\begin{array}{c}274.2 \\
326.0 \mathrm{sh}^{\mathrm{d}} \\
456.4\end{array}$ & $\begin{array}{l}22.74 \\
10.75 \\
22.98\end{array}$ & & 520.3 & 0.105 & 8.00 & 0.84 \\
\hline $\begin{array}{c}\text { Ethanol }^{\mathrm{c}} \\
(51.9)\end{array}$ & $\begin{array}{l}267.3 \\
330.7 \\
466.3\end{array}$ & $\begin{array}{c}3.17 \\
10.02 \\
24.69\end{array}$ & 450 & 532.4 & 0.0522 & 7.98 & 0.41 \\
\hline $\begin{array}{c}\text { Ethanol }^{\mathrm{c}} \text { :water } \\
8: 2 \mathrm{v} / \mathrm{v} \\
(53.7)\end{array}$ & $\begin{array}{l}269.6 \\
334.2 \\
469.2\end{array}$ & $\begin{array}{c}3.42 \\
11.73 \\
31.78\end{array}$ & & 535.1 & 0.0265 & 6.46 & 0.17 \\
\hline
\end{tabular}

${ }^{\mathrm{a}}$ Obtained by $\mathrm{A}$ or B procedure (Scheme 1 ); ${ }^{\mathrm{b})}$ concentration of $\mathbf{3}=4.09 \times 10^{-5} \mathrm{M}$. ${ }^{\mathrm{c}}$ Absolute ethanol; ${ }^{\mathrm{d})} \mathrm{sh}=$ shoulder. ${ }^{\mathrm{e}}$ Compared to quinine bisulfate (in $0.1 \mathrm{~N} \mathrm{H}_{2} \mathrm{SO}_{4}, \Phi=0.55$ ). ${ }^{\mathrm{f}}$ Estimated using the Strickler-Berg formula ${ }^{66}: \frac{1}{\tau_{0}}=2.88 \times 10^{-9} n^{2} \frac{\int I_{F}\left(v_{F}\right) d v_{F}}{\int I_{F}\left(v_{F}\right) v_{F}^{-3} d v_{F}} \times \int \frac{\varepsilon\left(v_{A}\right)}{v_{A}} d v_{A}$

where: $\tau_{0}$ is the lifetime, $v$ is the wavenumber of the maximum absorption band, $n$ is the refractive index of the solvent (1.3595 for ethanol), $I_{F}$ is the fluorescence intensity and $\varepsilon$, the molar absorption coefficient. ${ }^{\mathrm{g}} \tau=\tau_{0} \times \Phi$. 


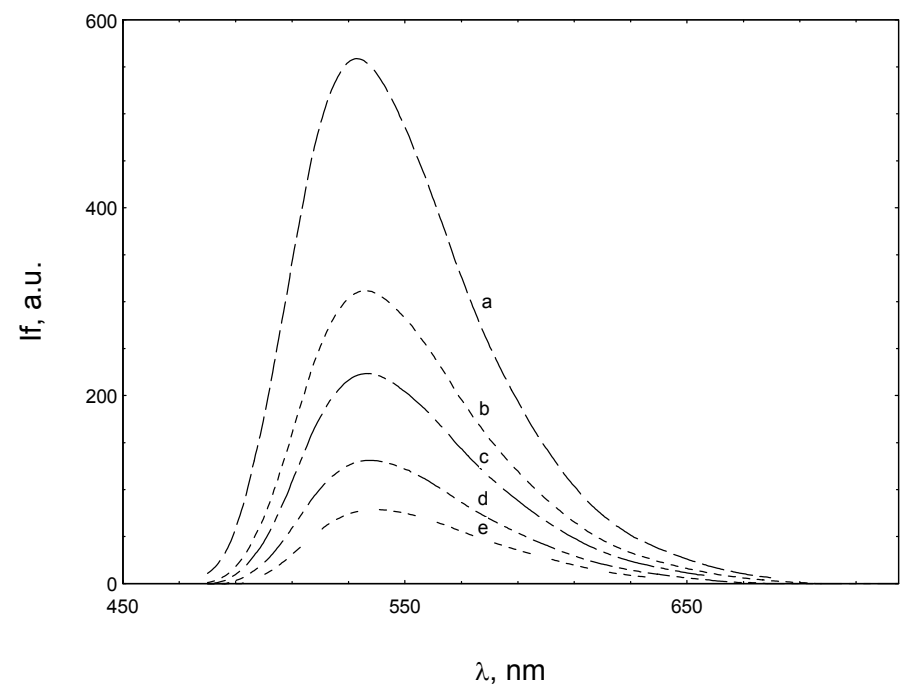

Figure 2. Change of the fluorescence intensity $\left(\lambda_{\mathrm{ex}}=450 \mathrm{~nm}\right)$ for compound $3(\alpha+\beta)$ : (concentration $=5.84 \times 10^{-5} \mathrm{M}$ ) in: $\mathrm{a}=$ ethanol; $\mathrm{b}=80 \%$ ethanol-water; $\mathrm{c}=60 \%$ ethanol-water; $\mathrm{d}$ $=40 \%$ ethanol-water; $\mathrm{e}=20 \%$ ethanol-water.

\section{Analysis of glucosamine in pharmaceutical preparations}

As mentioned earlier, salts of D-glucosamine with hydrochloric or sulfuric acid are used therapeutically for treatment and functional maintenance of cartilage in joints, and under the form of nutritional supplements. ${ }^{10,67}$ Often they are associated with chondroitin sulfate..$^{67,68}$

For analytical and bioanalytical qualitative or quantitative determinations of $\mathbf{3}(\alpha+\beta)^{8,15-33}$ one may use TLC as a simpler alternative to electrophoresis ${ }^{34}$ or HPLC. ${ }^{16}$ The procedure involves reacting 5 to $10 \mathrm{mg}$ of powdered pharmaceutical preparation either with $\mathbf{1}$ or with $\mathbf{4 a}$, in conditions described in the Experimental Part, followed by TLC analysis for qualitative analysis (one or two spots depending on the adsorbant and solvent) or by quantitative densitometry when the detection involves UV-Vis or fluorescence spectroscopy.

\section{Conclusions}

NMR spectra of the fluorescent compound $\mathbf{3}$ (synthesized by a novel method using glucosamine 1 and 7-aryloxy-4-nitrobenzofurazans 4 or 5) provided evidence for the two $\alpha$ and $\beta$ anomers. They could be visualized by TLC under special conditions of solid phase and solvent mixture. The less sterically hindered $\beta$ anomer is present in slighly higher concentration in the equilibrium mixture. By contrast, the $\alpha$ and $\beta$ anomers of analogous polynitrophenyl-substituted compounds 8 and 9 cannot be separated by TLC although their presence is proved by NMR spectra; in this case, probably owing to the higher electronegativity and better hydrogen-bond acceptor properties of ortho-situated nitro groups, the $\alpha$ anomer appears to predominate in the equilibrium 
mixture. The solvent polarity influences markedly the UV-Vis and fluorescence spectra of $\mathbf{3}(\alpha+$ $\beta$ ). The TLC method may be applied for determining the presence of glucosamine in pharmaceutical preparations.

\section{Experimental Section}

General Procedures. Commercial products were employed: D-glucosamine hydrochloride 1 (Acros Organics), 2 (Aldrich), 4a-e and 5, 55-37 6 (Merck), 7, ${ }^{69}$ TLC analytical silica gel plates $\mathrm{GF}_{254}$, TLC preparative silica gel plates PLC- $\mathrm{F}_{254}$, TLC analytical silica gel plates RP-18 $\mathrm{F}_{254}$ and HPTLC analytical plates CHIR (Merck).

${ }^{1} \mathrm{H}-\mathrm{NMR}$ and ${ }^{13} \mathrm{C}-\mathrm{NMR}$ spectra were recorded with a Varian Gemini 300BB spectrometer (300MHz for ${ }^{1} \mathrm{H}$ and $75 \mathrm{MHz}$ for ${ }^{13} \mathrm{C}$ ). We used Camag Software 1992 scanner II - Switzerland for densitometric TLC analysis. Temperatures were recorded with a digital termometer Diplex $\left(-40^{\circ} \mathrm{C}\right.$ to $\left.200^{\circ} \mathrm{C}\right)$. The absorption spectra were recorded with Perkin Elmer Lambda $35 \mathrm{UV}$-vis spectrometer; conditions are specified in Table 6. For fluorescence spectra, a Perkin-Elmer 204 spectrofluorimeter was used; conditions are specified in Table 6. For fluorescence, an excitation lamp $(\mathrm{Xe}, 150 \mathrm{~W})$ interfaced with the computer was used, allowing a pre-established data reading time of $0.5 \mathrm{~s}$; IR spectra were recorded with FTIR spectrophotometer Bruker-Model Vertex 70, using ATR techniques. Melting points have been recorded in open capillary with Electrothermal IA 9000 Series of digital melting point instruments.

\section{Synthesis of compounds $3(\alpha+\beta), 8(\alpha+\beta)$ and $9(\alpha+\beta)$. General procedure}

Variant A was applied for obtaining compounds $\mathbf{3 , 8}$, and $\mathbf{9}$. Starting from D-gluocosamine $\mathbf{1}$ (as hydrochloride) and halogen derivatives 2, 6, 7 (molar ratio 1:1) in methanol (5 $\mathrm{mL}$ for one gram of reactant mixture) and sodium hydrogen carbonate ( 2.5 moles for each mole of reactant $\mathbf{1})$ the reaction mixture was stirred at $50^{\circ} \mathrm{C}$ (for 3 during $1 \mathrm{~h}$, for 8 during $24 \mathrm{~h}$, and for 9 during 7 days). The reaction mixture was filtered and the filtrate was evaporated under vacuum. The residue was purified by preparative TLC using preparative silica gel TLC plates PLC- $\mathrm{F}_{254}$ (Merck): for $\mathbf{3}$, the mobile phase was dichloromethane: methanol 8.5:1.5, v/v; for $\mathbf{8}$ and 9, dichloromethane: methanol 9:1, v/v. Fluorescence detection was used at $360 \mathrm{~nm}$ for 3, and at $254 \mathrm{~nm}$ for 8 and 9. The area of maximum concentration was retained and extracted in a Soxhlet with dichloromethane:methanol $(9: 1, \mathrm{v} / \mathrm{v})$, followed by evaporation under vacuum. With TLC using silica gel $\mathrm{GF}_{254}$ (Merck) analytical plates, methylene chloride:methanol 8.5:1.5 v/v, two spots were detected by densitometric analysis.

Variant B was used only for $\mathbf{3}(\alpha+\beta)$ starting from D-glucosamine $\mathbf{1}$ (as hydrochloride) and $\mathbf{4 a}$ (molar ratio 1:1.2) in the presence of $\mathrm{NaHCO}_{3}$ in methanol (5 $\mathrm{g}$ for one gram of reactant mixture) at $30^{\circ} \mathrm{C}$ for $24 \mathrm{~h}$. The reaction mixture was then worked up as indicated above, and the product 3 was indistinguishable from that obtained by variant A. With compounds $4 \mathbf{b}-\mathbf{4 e}$ or 5 , similar results were obtained. 
2-[N-(7'-Nitrobenz-2'-oxa-1',3'-diazol-4'-yl)amino]-2-deoxy-D-glucose (3) $(\boldsymbol{\alpha}+\boldsymbol{\beta})$. Orangecolored, 40\% yield (variant A), or $60 \%$ (variant B), m.p. 159-160 ${ }^{\circ} \mathrm{C}$; Anal.: Calcd. for $\mathrm{C}_{12} \mathrm{H}_{14} \mathrm{~N}_{4} \mathrm{O}_{8}$ : C 42.11; $\mathrm{H} 4.12$; $\mathrm{N} \mathrm{16.36;} \mathrm{found} \mathrm{C} 41.9 ; \mathrm{H} 4.8 ; \mathrm{N} \mathrm{16.30 \%}$. ${ }^{1} \mathrm{H}-\mathrm{NMR}$ (in dmso$\mathrm{d}_{6}+\mathrm{TFA}, \delta$ ppm, $\left.J \mathrm{~Hz}\right)$ : 9.42(bs, 1H, NH); 8.50(d, 1H, 9.1, H-6'); 6.90(d, 1H, 9.1, H-5'); 5.23(d, $0.5 \mathrm{H}, \mathrm{H}-1 \alpha, 3.2) ; 4.78(\mathrm{~d}, 0.5 \mathrm{H}, \mathrm{H}-1 \beta, 8.6) ; 4.07-3.48(\mathrm{~m}, 4 \mathrm{H}, \mathrm{H}-2-3-4-5) ; 3.36-3.14(\mathrm{~m}, \mathrm{AB}$ system, 2H, H-6A and H-6B). ${ }^{13} \mathrm{C}-\mathrm{NMR}$ (dmso-d $\left.{ }_{6}+\mathrm{TFA}, \delta \mathrm{ppm}\right): 147.05\left(\mathrm{C}-7^{\prime}\right)$; $145.14\left(\mathrm{C}^{\prime} 4^{\prime}\right)$; 144.81(C-1'a); 138.42(C-6'); 120.80(C-3'a); 100.88(C-5'); 77.53(CH-1); 75.14(CH-3); 72.92(CH-4); 71.93(CH-5); 71.14(CH-2); 61.58(C-6).

2-[N-(2',4',6'-Trinitrophenyl)amino]-2-deoxy-D-glucose $8(\boldsymbol{\alpha}+\boldsymbol{\beta})$. Yellow, 50\% yield, m.p. 103-104 ${ }^{\circ} \mathrm{C}$; Anal.: Calcd. for $\mathrm{C}_{12} \mathrm{H}_{14} \mathrm{~N}_{4} \mathrm{O}_{11}$ : C 36,93; H 3.61; N 14.35; found C 36.90; $\mathrm{H} \mathrm{3.58;} \mathrm{N}$ 14.31\%; IR (solid ATR), $\mathrm{cm}^{-1}$ : 1590, $1618\left(\mathrm{NO}_{2}\right), 2852,2922\left(\mathrm{CH}, \mathrm{CH}_{2}\right), 3295(\mathrm{OH}) ;{ }^{1} \mathrm{H}-\mathrm{NMR}$

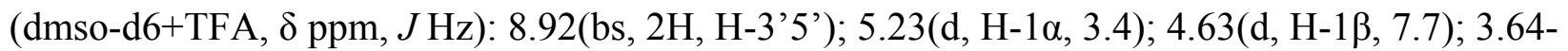
3.42(m, 3H, H-3-4-6A); 3.10-3.03(m, 2H, H-2-5); 3.00(dd, AB system, H-6B, 3.5, 9.7). ${ }^{13} \mathrm{C}-$ NMR (dmso-d $6, \delta$ ppm): 143.01(C-1'); 138.87(C-2'-6'); 133.50(C-4'); 127.09(C-3'-5'); 89.29(CH-1); 73.71(CH-3); 72.56(CH-4); 69.56(CH-5); 61.30(CH-2); 60.58( $\left.\mathrm{CH}_{2}-6\right) .{ }^{13} \mathrm{C}-\mathrm{NMR}$ (dmso-d ${ }_{6}+$ TFA, $\delta$ ppm): 143.29(C-1'); 137.69(C-4'); 133.73(C-2'-6'); 127.23(C-3'-5'); 89.56(CH-1); 73.96(CH-3); 72.78(CH-4); 69.81(CH-5); 61.54(CH-2); 60.81( $\left.\mathrm{CH}_{2}-6\right)$.

2-[N-(2',4'-Dinitrophenyl)amino]-2-deoxy-D-glucose $9(\boldsymbol{\alpha}+\boldsymbol{\beta})$. Yellow, 46\% yield, m.p. 192$194^{\circ} \mathrm{C}$ (lit. $194-196^{\circ} \mathrm{C}^{38,39}$ and $201-203^{\circ} \mathrm{C}{ }^{38,39}$ ); Anal.: Calcd. for $\mathrm{C}_{12} \mathrm{H}_{15} \mathrm{~N}_{3} \mathrm{O}_{9}$ : C 41,74; $\mathrm{H} 4.37$; N 12.17; found C 41.71; H 4.35; N 12.13\%; IR (solid ATR), $\mathrm{cm}^{-1}$ : 1585, $1615\left(\mathrm{NO}_{2}\right), 2853,2920$ $\left(\mathrm{CH}, \mathrm{CH}_{2}\right), 3320(\mathrm{OH}) ;{ }^{1} \mathrm{H}-\mathrm{NMR}$ (dmso-d 6 TFA, $\delta$ ppm, $\left.J \mathrm{~Hz}\right)$ : 8.84(d, 1H, H-3', 2.4); 8.19(dd,

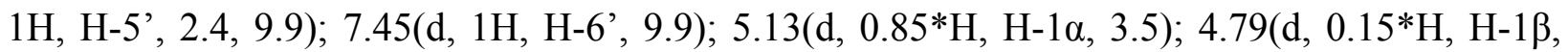
7.5); 3.72-3.28(m, 6H, H-2-3-4-5-6). ${ }^{13} \mathrm{C}-\mathrm{NMR}$ (dmso-d6+TFA, $\delta$ ppm): 149.50(C-1'); 135.45(C-4'); 130.05(C-2'); 129.80(C-3’); 123.84(C-5’); 117.69(C-6’); 90.90(C-1); 74.11(C-3); 72.89(C-4); 70.64(C-5); 61.42(C-2); 57.95(C-6).

\section{Determination of D-glucosamine (1) from pharmaceutical preparations}

Finely ground (5 to $10 \mathrm{mg}$ ) preparation was suspended in $2 \mathrm{~mL}$ of methanol and stirred at $50^{\circ} \mathrm{C}$ for $10 \mathrm{~min}$. The filtered solution was treated with a slight excess of $\mathrm{NaHCO}_{3}$ for neutralizing the acids accompanying the D-glucosamine and/or chondroitin, stirred for $15 \mathrm{~min}$. then treated with two molar equivalents of $\mathbf{2}$ or $\mathbf{4 a}$ and stirred at $50^{\circ} \mathrm{C}$ for another $10 \mathrm{~min}$. (when using 2) or 30 min. (when using 4a). One more $\mathrm{mL}$ of methanol was added to the reaction mixture. Then $5 \mu \mathrm{L}$ of this solution was subjected to TLC in one of the following alternatives: (i) analytical silica gel plates RP-18F 254 (Merck), mobile phase ethanol:water (6:3, v/v), producing one spot; (ii) HPTLC analytical plates CHIR (Merck), mobile phase $\mathrm{H}_{2} \mathrm{O}: \mathrm{EtOH}(9: 1, \mathrm{v} / \mathrm{v})$, producing two spots; (iii) analytical silica gel plates $\mathrm{GF}_{254}$ (Merck), mobile phase dichloromethane:methanol $(8.5: 1.5, \mathrm{v} / \mathrm{v})$, producing two spots. The detection was achieved either by UV-Vis at $254 \mathrm{~nm}$, or by fluorescence at $360 \mathrm{~nm}$. 


\section{References}

1. Ghosh, P. B.; Whitehouse, M. W. J. Med. Chem. 1968, 11, 305.

2. Ghosh, P. B.; Whitehouse, M. W. Biochem. J. 1968, 108, 155.

3. Birkett, D. J.; Price, N. C.; Radda, G. K.; Salmon, A. G. FEBS Lett. 1970, 6, 346.

4. Kenner, R. A.; Aboderin, A. A. Biochemistry 1971, 10, 4433.

5. Imai, K.; Toyo'oka, T.; Miyano, H. Analyst 1984, 109, 1365.

6. Bem, M.; Caproiu, M. T.; Vasilescu, M.; Tudose, M.; Socoteanu, R.; Nicolae, A.; Constantinescu, T.; Banciu, M. D. Rev. Roum. Chim. 2003, 48, 709.

7. Bem, M.; Badea, F.; Draghici, C.; Caproiu, M. T.; Vasilescu, M.; Voicescu, M.; Beteringhe, A.; Caragheorgheopol, A.; Maganu, M.; Constantinescu, T.; Balaban, A. T. ARKIVOC, 2007, (xiii), 87.

8. Haugland, R. P. The Handbook. A Guide to Fluorescent Probes and Labeling Technologies, ${ }^{\text {th }}$ Edn., Molecular Probes, 2005, pp 87, 105, 127, 272, 591, 610, 618, 713, 794, 873.

9. Crampton, M. R.; Delaney, J.; Rabbitt, L. C. J. Chem. Soc., Perkin Trans. 2 1999, 2473.

10. The Merck Index, $14^{\text {th }}$ Edn., Merck \& Co., Inc., Whitehouse Station, N.J., USA, 2006, pp $341,769$.

11. Alok, R. R.; Dinesh, K. J. Macromol. Sci. 2000, C40, 69.

12. Kailash, C. G., J. Macromol. Sci. 2000, C40, 273.

13. Shanmugasundaram, O. L., J. Textile Apparel, Technol. Management 2006, 5, 1.

14. Amaral, I. F.; Granja, P. L.; Barbosa, M. A. J. Biomater. Sci. Polymer Edn. 2005, 16, 1575.

15. Yoshioka, K.; Takahashi, H.; Homma, T.; Saito, M.; Oh, K.-B.; Nemoto, Y.; Matsuoka, H. Biochim. Biophys. Acta 1996, 1289, 5.

16. Yamada, K.; Saito, M., Matsuoka, H.; Inagaki, N. Nature Protocols 2007, 2, 753.

17. Banning, U.; Barthel, H.; Mauz-Körholz, C.; Kluge, R.; Körholz, D.; Sabri O. Eur. J. Haematol. 2006, 77, 102.

18. Ito, I.; Watanabe, S.; Kirino, Y. Neurosci. Lett. 2006, 398, 224.

19. Zou, C.; Wang, Y.; Shen, Z. J. Biochem. Biophys. Methods 2005, 3, 207.

20. Achilles, J.; Müller, S.; Bley, T.; Babel, W. Cytometry 2004, 61A, 88.

21. Ball, S. W.; Bailey, J. R.; Stewart, J. M.; Vogels, C. M.; Westcott, S. A. Can. J. Physiol. Pharmacol. 2002, 80, 205.

22. Oh, K. B.; Matsuoka, H. Int. J. Food Microbiol. 2002, 76, 47.

23. Leira, F.; Louzao, M. C.; Vieites, J. M.; Botana, L. M.; Vieytes, M. R. Toxicol. in Vitro 2002, 16, 267.

24. Matsuoka, H.; Kurokawa, T.; Oishi, K.; Saito, M. J. Food Safety 2002, 22, 141.

25. Natarajan, A.; Srienc, F. J. Microbiol. Methods 2000, 42, 87.

26. Yamada, K.; Nakata, M.; Horimoto, N.; Saito, M.; Matsuoka, H.; Inakaki, N. J. Biol. Chem. 2000, 275, 22278. 
27. Matsuoka, H.; Oishi, K.; Watanabe, M.; Kozone, I.; Saito, M.; Igimi, S. Biosci. Biotechnol. Biochem. 2003, 67, 2459.

28. Loaiza, A.; Porra, O. H.; Barros, L. F. J. Neurosci. 2003, 23, 7337.

29. Porras, O. H.; Loaiza, A.; Barros, L. F. J. Neurosci. 2004, 24, 9669.

30. Bernardinelli, Y.; Magistretti, P. J.; Chatton, J.-Y. Neurosci. 2004, 101, 14937.

31. Chen, X.-M.; O’Hara, S. P.; Huang, B. Q.; Splinter, P. L.; Nelson, J. B.; LaRusso, N. F. Cell Biol. 2005, 102, 6338.

32. Etxeberria, E.; González, P.; Tomlinson, P.; Pozueta-Romero, J. J. Exper. Botany 2005, 56, 1905.

33. Hilt, J. Z.; Byrne, M. E.; Peppas, N. A. Chem. Mater. 2006, 18, 5869.

34. Suzuki, S.; Shimotsu, N.; Honda, S.; Arai, A.; Nakanishi, H. Electrophoresis 2001, 22, 4023.

35. Bem, M.; Caproiu, M. T.; Stoicescu, D.; Constantinescu, T.; Balaban A.T. Central Eur. J. Chem. 2003, 3, 260.

36. Bem, M.; Culita, D. C.; Caproiu, M. T.; Constantinescu, T.; Banciu M. D. Rev. Roum. Chim. 2003, 48,387.

37. Bem, M.; Vasilescu, M.; Caproiu, M. T.; Draghici, C.; Beteringhe, A.; Constantinescu, T.; Banciu, M. D.; Balaban, A. T. Central Eur. J. Chem. 2004, 2, 672.

38. Lloyd, P. F.; Stacey, M. Tetrahedron 1960, 9, 116.

39. Okotore, R. O. Can. J. Chem. 1976, 54, 1394.

40. Domszy, J. G.; Roberts, G. A. F. Internat. J. Biol. Macromol. 1985, 7, 45.

41. Kaifu, R.; Osawa, T. Carbohydrate Res. 1977, 58, 235.

42. Lloyd, P. F.; Evans, B.; Fielder, R. J. Carbohydrate Res. 1969, 9, 471.

43. Cantley, M.; Hough, L. J. Chem. Soc. 1963, 2711.

44. Moutires, G.; Pinson, J.; Terrier, F.; Goumont, R. Chem. Eur. J. 2001, 7, 1712.

45. Breitmaier, E.; Voelter, W. Carbon-13 NMR Spectroscopy. High-Resolution Methods and Applications in Organic Chemistry and Biochemistry, VCH: New York, Weinheim, 1990; pp 388.

46. Bell, R. P. The Proton in Chemistry, Methuen: London, 1959.

47. Bell, R. P. Acid-Base Catalysis, Clarendon Press: Oxford, 1941.

48. www.hyper.com/products/evaluation/hyper75/default.html

49. Shchepin, R.; Litvinov, D. http://www.psu.ru/science/soft/winmopac/index e.html

50. Katritzky, A. R.; Lobanov V. S.; Karelson, A. CODESSA: A Reference Manual (Version 2.0), Gainesville, Florida, 1994.

51. http://www.arguslab.com

52. Linnanto, J.; Korppi-Tommola, J. J. Comput. Chem. 2003, 25, 123.

53. Khan, A. J. Phys. Chem. 2000, 104, 11268.

54. Cserhati, T.; Forgacs, E. J. Chromatogr. A 1994, 660, 313.

55. Kossoy, A. D.; Risley, D. S.; Kleyle, R. M.; Nurok, D. Anal. Chem. 1992, 64, 1345.

56. Soczewinski, E. Anal. Chem.90 1969, 41, 179. 
57. Calvino, R.; Gasco, A.; Leo, A. J. Chem. Soc., Perkin Trans. 2 1992, 1643.

58. Hansch, C.; Leo, A. Substituent Constants for Correlation Analysis in Chemistry and Biology, Wiley: New York, 1979.

59. Davankov, V. A.; Zolotarev, Yu. A. J. Chromatogr. 1978, 155, 285.

60. Davankov, V. A.; Zolotarev, Yu. A. J. Chromatogr. 1978, 155, 295.

61. Siouffi, A.-M.; Piras, P.; Roussel, C. J. Planar Chromatogr. 2005, 18, 5.

62. Reeves, R. E.; Jung, Jr., J. R. J. Am. Chem. Soc. 1949, 71, 209.

63. Reeves, R. E. J. Am. Chem. Soc. 1949, 71, 212.

64. Reeves, R. E. J. Am. Chem. Soc. 1949, 71, 215.

65. Reichardt, C. Solvents and Solvent Effects in Organic Chemistry, $3^{\text {rd }}$ Edn., Wiley-VCH: New York, 2003; p 352.

66. Strickler, S. J.; Berg, R. J. Chem. Phys. 1962, 37, 814.

67. Kelly, G. S. Alternative Medicine Review, 1998, 3, 27.

68. Mazie'res, B.; Hucher, M.; Zaïm, M.; Garnero, P. Ann. Rheum. Dis. 2007, 66, 639.

69. Ionita, P.; Caproiu, M. T.; Balaban, A. T. Rev. Roum. Chim. 2000, 45, 935. 